\title{
Imaging Aortic Regurgitation: The Incremental Benefit of Speckle Tracking Echocardiography
}

\author{
Pankaj Garg ${ }^{1,2, *}$, Firas Yassin ${ }^{1}$, and Roman Leischik ${ }^{3}$ \\ ${ }^{I}$ Cardiothoracic Unit, Chesterman Wing, Northern General Hospital, Sheffield Teaching Hospitals NHS Foundation \\ Trust, Sheffield, UK \\ ${ }^{2}$ Multidisciplinary Cardiovascular Research Centre \& Leeds Institute for Cardiovascular and Metabolic Medicine, \\ University of Leeds, Leeds, UK \\ ${ }^{3}$ Witten/Herdecke University, Faculty of Health, School of Medicine, Cardiology, Hagen, Germany
}

\begin{abstract}
Aortic regurgitation (AR) affects global left ventricular mechanics. However, limited literature is available on how it may affect regional longitudinal strain.

We present a case where severe AR jet is thrashing the anterior-septal wall and reducing its overall longitudinal performance most likely secondary to increased wall shear stress in diastole. This new insight into patho-physiological process using deformation study may have supplementary impact in decision making for surgical intervention. Transthoracic echocardiography is the primary imaging modality for the assessment of AR as it offers evaluation of severity of AR, aetiology of AR, left ventricular (LV) dilatation, LV systolic function, left ventricular mass, diastolic function and global strain. This case highlights the regional disturbances in longitudinal strain in eccentric AR.
\end{abstract}

Keywords: Aortic regurgitation, cardiac mechanics, ejection fraction, strain, ultrasound imaging.

\section{INTRODUCTION}

Aortic regurgitation (AR) results from disease of either the aortic leaflets or the aortic root that distorts the leaflets to prevent their correct apposition. Transthoracic echocardiographic (TTE) assessment remains the first-line imaging modality to clarify the aetiology, the lesion process, and the type of dysfunction [1]. Some recent studies have shown incremental value of assessment of global left ventricular mechanics (strain, strain rate) in asymptomatic patients with aortic regurgitation [2-4]. One study showed reduced basal longitudinal strain in patients with mild aortic regurgitation [5]. However, we did not identify any study, which looked at the characteristics of the jet of AR affecting regional longitudinal function.

\section{CASE REPORT}

We report a case of 45-year-old lady who was referred for echocardiographic study as she had an incidental finding of diastolic murmur by her primary care physicians. Her past medical history was unremarkable and she remained asymptomatic. Transthoracic echocardiography was

*Address correspondence to this author at the Department of Cardiology and Cardio-thoracic Surgery, Chesterman Wing, Northern General Hospital, Sheffield Teaching Hospitals NHS Foundation Trust, Herries Road, Sheffield S5 7AU, UK; Tel: +44-114-226-6115; Fax: +44-114-261-0350;

E-mail: Pankaj.Garg@sth.nhs.uk performed using an EPIQ 7C (Philips, Best, Netherlands) in accordance with British Society of Echocardiography (BSE) recommendations, with QLAB (Software Version 10, Philips, Best, Netherlands) post processing software. Her examination showed the presence of severe AR (vena contracta of the jet was greater than $7 \mathrm{~mm}$; the AR jet covered greater than $75 \%$ of LVOT area; speckle doppler density of the AR jet was high) (Fig. 1). Baseline echocardiographic parameters were as follows interventricular thickness in end-diastole (IVSd) $=10 \mathrm{~mm}$, left ventricular end diastolic diameter $($ LVEDd $)=62 \mathrm{~mm}, \mathrm{LV}$ end-systolic diameter (LVSDd) $=49 \mathrm{~mm}$, posterior wall thickness in end-diastole (LVPWd) $=10 \mathrm{~mm}$, the left ventricular ejection fraction by Simpson's bi-plane method was $54 \%$, the LV mass was $271 \mathrm{~g} / \mathrm{cm}^{2}$ and the E/A ratio was 0.84. Global Longitudinal Strain (GLS) and Global Circumferential Strain (GCS) were analysed using the online Cardiac Motion Quantification (CMQ) tool on EPIQ system. Bull's Eye plot of the regional longitudinal and circumferential strain were obtained and analysed. The regional longitudinal strain was reduced in the anteriorseptal walls thrashed by the aortic regurgitation jet (Fig. 2). The most likely explanation for this phenomenon is the high wall shear stress (WSS) due to AR jet causing microvascular dysfunction in the sub-endocardial longitudinal fibres of the anterior-septal wall. In this patient's case, an urgent referral to cardiology team was suggested for further assessment of surgical intervention. 


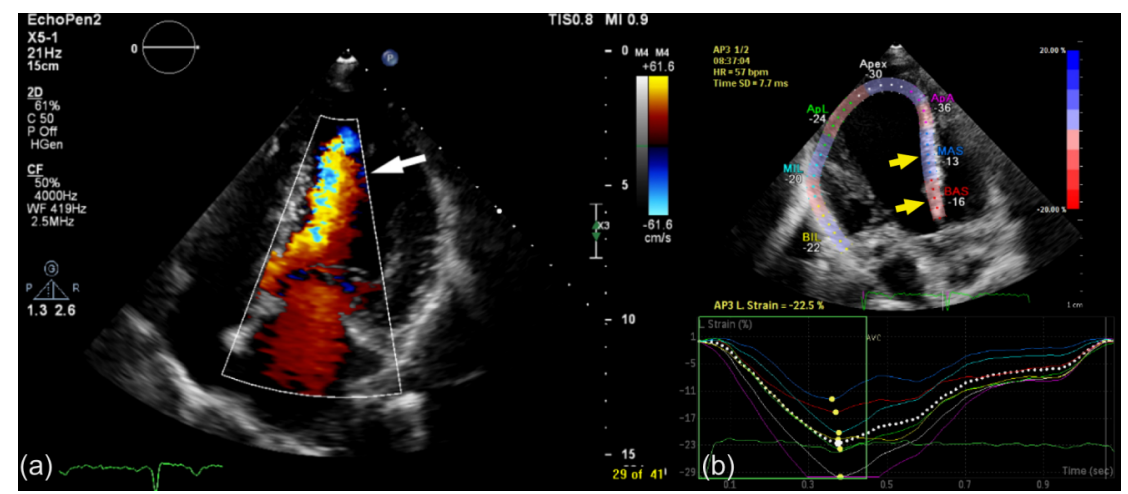

Fig. (1). (a) Apical five-chamber view with colour Doppler showing severe eccentric jet of AR thrashing the interventricular septum (white arrow). (b) Reduced basal and mid anterior-interventricular septal longitudinal strain compared to other regions.

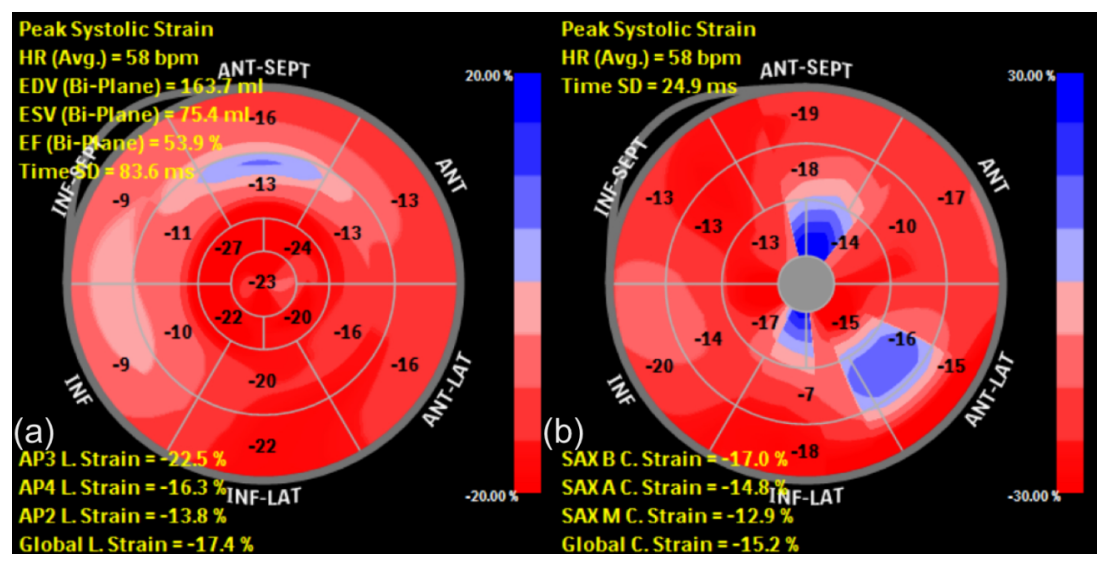

Fig. (2). (a) Bulls-Eye plot of longitudinal strain showing reduced stain in the interventricular septum (blue area). (b) Bulls-Eye plot of circumferential strain of 16-segments showing regional reduction in lateral, anterio-septum and apex.

\section{DISCUSSION}

The incidence of aortic regurgitation increases with age and reported prevalence is around 4-5\% [6]. Moderate to severe AR contributes $0.5 \%$ of all cases. As the aortic incompetency worsens, volume overload of the LV ensues. This is initially masked by improvement in the LV ejection fraction due to compensatory increase in the LV enddiastolic volume [7]. However, as the LV de-compensates, and the LV end-diastolic pressure (LVEDP) rises, LV ejection fraction pseudo-normalises and then deteriorates. This is when the patients are likely to become symptomatic [8]. Early adaptation of the LV is initially reversible, and LV systolic function can recover after restoration of normal loading conditions by aortic valve replacement surgery. With no intervention at this stage, myocardial contractile dysfunction may develop, at which point there is greater risk of irreversible LV dysfunction and poorer outcomes.

Even though several studies have assessed the role of non-invasive imaging in predicting long-term outcomes in these patients, there remains paucity of quantifiable parameters that possibly reflect early adaptation of the LV at rest echocardiogram.

Strain assessment on echocardiography has the advantage to quantify regional longitudinal, radial and circumferential strain $[9,10]$. LV deformation assessment can identify subtle changes in regional myocardial function even before the standard left ventricular parameters of function start to deteriorate [11]. Hence, both regional strain and global strain assessment may be valuable in the assessment of these patients who remain asymptomatic with significant AR. As strain derived parameter on echocardiography have shown robust reproducibility [12], followed-up scans could assess if there is deterioration of myocardial deformation.

In our case, there was reduction in global deformation parameters $(\mathrm{GLS}=-17.4 \% ; \mathrm{GCS}=-15.2 \%)$ and also there was regional variation of strain. As previously mentioned, regional longitudinal strain parameters were more affected in segments where AR jet was touching the endocardium on Doppler echocardiography. This would increase the regional WSS resulting in compromised diastolic myocardial blood flow and decreased longitudinal regional deformation.

\section{CONCLUSION}

Regional myocardial deformation assessment may play an important role in the clinical follow-up assessment of patients with eccentric AR. This is, to our knowledge, the first reported case where use of speckle tracking echocardiography (STE) has identified conceivable 
association of an eccentric AR jet to regional disturbance in the longitudinal function of the left ventricle.

Large-scale studies using advanced imaging techniques, such as STE, are warranted to clarify their potential clinical role in the detection subclinical myocardial involvement in patients with aortic regurgitation and it's potential prognostic role.

\section{CONFLICT OF INTEREST}

The authors confirm that this article content has no conflict of interest.

\section{ACKNOWLEDGEMENTS}

Declared none.

\section{LIST OF ABBREVIATIONS}

$\begin{array}{ll}\text { AR } & =\text { Aortic Regurgitation } \\ \text { LV } & =\text { Left Ventricle } \\ \text { TTE } & \text { Transthoracic Echocardiogram } \\ \text { LVOT } & \text { Interventricular septal end-diastolic diameter } \\ \text { IVSd } & \text { Left ventricular end-diastolic diameter } \\ \text { LVEDd } & \text { Left ventricular end-systolic diameter } \\ \text { LVSDd } & \text { Left ventricular posterior end-diastolic } \\ \text { LVPWd } & \text { diameter } \\ \text { GLS } & \text { Global Longitudinal Strain } \\ \text { GCS } & \text { Global Circumferential Strain } \\ \text { CMQ } & \text { Cardiac Motion Quantification } \\ \text { WSS } & \text { Wall Shear Stress } \\ \text { STE } & =\text { Speckle Tracking Echocardiography }\end{array}$

\section{REFERENCES}

[1] Lancellotti P, Tribouilloy C, Hagendorff A, et al. Recommendations for the echocardiographic assessment of native valvular regurgitation: An executive summary from the European Association of Cardiovascular Imaging. Eur Heart J Cardiovasc Imag 2013; 14: 611-44.

[2] Kusunose K, Agarwal S, Marwick TH, Griffin BP, Popović ZB. Decision making in asymptomatic aortic regurgitation in the era of guidelines: incremental values of resting and exercise cardiac dysfunction. Circ Cardiovasc Imaging 2014; 7(2): 352-62.

[3] Leonardi B, Margossian R, Sanders SP, Chinali M, Colan SD Ventricular mechanics in patients with aortic valve disease: longitudinal, radial, and circumferential components. Cardiol Young 2014; 24(1): 105-12.

[4] Li CM, Li C, Bai WJ, et al. Value of three-dimensional speckletracking in detecting left ventricular dysfunction in patients with aortic valvular diseases. J Am Soc Echocardiogr 2013; 26(11): 1245-52.

[5] Stefani L, De Luca A, Maffulli N, et al. Speckle tracking for left ventricle performance in young athletes with bicuspid aortic valve and mild aortic regurgitation. Eur J Echocardiogr 2009; 10(4): 52731.

[6] Lebowitz NE, Bella JN, Roman MJ, et al. Prevalence and correlates of aortic regurgitation in American Indians: the Strong Heart Study. J Am Coll Cardiol 2000; 36(2): 461-7.

[7] Rigolin VH, Bonow RO. Hemodynamic characteristics and progression to heart failure in regurgitant lesions. Heart Fail Clin 2006; 2 (4): 453-60.

[8] Saura D, Peñafiel P, Martínez J, et al. The frequency of systolic aortic regurgitation and its relationship to heart failure in a consecutive series of patients. Rev Española Cardiol 2008; 61(7): $771-4$.

[9] Ferferieva V, Van den Bergh A, Claus $\mathrm{P}$, et al. The relative value of strain and strain rate for defining intrinsic myocardial function. Am J Physiol Heart Circ Physiol 2012; 302(1): H188-95.

[10] Serri K, Reant P, Lafitte M, et al. Global and regional myocardial function quantification by two-dimensional strain: application in hypertrophic cardiomyopathy. J Am Coll Cardiol 2006; 47(6): $1175-81$.

[11] Feigenbaum H, Mastouri R, Sawada S. A practical approach to using strain echocardiography to evaluate the left ventricle. Circ J 2012; 76(7): 1550-5.

[12] Leischik R, Dworrak B, Hensel K. Intraobserver and interobserver reproducibility for radial, circumferential and longitudinal strain echocardiography. Open Cardiovasc Med J 2014; 8: 102-9.

(C) Garg et al.; Licensee Bentham Open.

This is an open access article licensed under the terms of the Creative Commons Attribution Non-Commercial License (http://creativecommons.org/licenses/by$\mathrm{nc} / 4.0 /$ ), which permits unrestricted, non-commercial use, distribution and reproduction in any medium, provided the work is properly cited. 